The outsourcing of health, sport and physical educational work: A state of play

Benjamin J. Williams, Peter J. Hay and Doune Macdonald

School of Human Movement Studies, The University of Queensland, Brisbane, Australia

Benjamin J. Williams

School of Human Movement Studies

The University of Queensland

Brisbane, Queensland, Australia, 4072

Phone: +61733656313

Fax: +617 33656877

Email: benjamin.williams3@uqconnect.edu.au 


\section{The outsourcing of health, sport and physical educational work: A state of play}

Background: The outsourcing of health, sport and physical educational (HSPE) work has been a feature of physical education (PE) 'futures talk' for over 20 years (Kirk, 2009). However, HSPE work outsourcing has been the focus of little empirical research and only occasional commentary. That small amount of empirical research that has been conducted has been narrow in scope, focusing exclusively on primary schools and at times presented data that are partial and fragmentary.

Purpose: The purpose of this paper was to investigate HSPE work outsourcing in the Australian state of Queensland. Specifically, we examined the prevalence of such outsourcing among Queensland schools, the ways that these schools were using it, and the reasons why they had done so.

Methods: A random, proportionately stratified sample of 846 Queensland schools was invited to participate in this study. This sample included government and non-government, primary, secondary, combined primarysecondary and special schools. Data were collected via a mixed-mode survey design that was implemented using Internet and paper-copy forms of a context specific 21-item questionnaire (Dillman et al., 2009).

Results: The questionnaire's response rate was $32 \%$. Simple relational analyses (Sarantakos 2005) of the data demonstrated that: (a) 85\% ( $n=230)$ of schools reported outsourcing some form of HSPE work in the previous twelve months; (b) many schools used outsourced HSPE work for outdoor adventure activities and extra-curricular activities; (c) $75 \%(\mathrm{n}=203)$ of all respondents engaged in some form of fee-based outsourcing and $83 \%$ of all outsourcing arrangements were fee-based; (d) the majority of schools paid for outsourced HSPE work using school funds or by charging participating students; and, (e) the most frequently reported reason for outsourcing HSPE work was to access external suppliers' expertise.

Conclusions: These data replicate some findings of previous research in a different research context as well as presenting forms of data on HSPE work outsourcing hitherto unreported. Furthermore, they demonstrate the ways in which HSPE work is embedded in broader social, political and economic shifts, particularly changing relations between capital, education and the state. Finally they also serve to prompt critical questions about why HSPE work is outsourced, how it is outsourced and the impact it has on the educational labour process and all those involved in it. We conclude that HSPE work outsourcing is a practice with the potential to significantly disturb labouring, learning and the politics of expertise as they relate to health, sport and physical education.

Keywords: outsourcing; educational work; physical education; school sport; external providers

\section{Practitioner summary}

The purpose of this paper was to investigate the outsourcing of health, sport and physical educational (HSPE) work in the Australian state of Queensland, its 
prevalence, the ways it was used, and the reasons why it was undertaken. Data were collected by surveying a sample of 846 government and non-government, primary, secondary, combined primary-secondary and special schools. The data obtained demonstrated that: (a) $85 \%(n=230)$ of schools reported outsourcing some form of HSPE work in the previous twelve months; (b) many schools used outsourced HSPE work for outdoor adventure activities and extra-curricular activities; (c) 75\% (n=203) of respondents engaged in fee-based outsourcing and $83 \%$ of all outsourced HSPE work was fee-based; (d) the majority of schools paid for outsourced HSPE work using school funds or by charging participating students; and, (e) the most frequently reported reason for outsourcing HSPE work was to access external suppliers' expertise. These data raise a number of important questions about the future of work and learning related to HSPE work, as well as the nature, value and politics of educational expertise. Thus, the practice of HSPE work outsourcing should therefore be a matter of considerable interest to physical educators.

\section{Introduction}

The outsourcing of health, sport and physical educational (HSPE) work ${ }^{1}$ has been a feature of physical education (PE) ‘futures talk' for over 20 years (Kirk 2009). Hoffman's (1987) satirical account of American PE in the Year 2020 is one such example. Hoffman 'dreamed the impossible dream', foretelling the demise of the PE teaching profession and the outsourcing of sport and exercise instruction to Pedasport Inc and 'self directed play managers'. Five years later, Hoffman's provocative piece inspired a similar piece of fortune telling: Tinning's (1992) 'not so sweet dream' about Australian PE at the dawn of the new millennium. Tinning foresaw a future where PE taught by school teachers gave way to sport education classes delivered by SportEd Inc and fitness sessions led by 'community sport volunteers'. 
Given the bleak futures prophesised by Hoffman and Tinning and the indications given by each that their predictions were already beginning to materialise, one might have anticipated a flurry of academic interest in the outsourcing of HSPE work. However, in the years since these pieces were published, the outsourcing of HSPE work has been the focus of little empirical research and only occasional commentary. Where data have been collected, the research has been of narrow scope, focusing only on primary schools (e.g. Ardzejewska 2009; Evans 1993; Griggs 2010; Lavin, Swindlehurst, and Foster 2008; Lynch 2007; Webster 2001). Furthermore, the data presented has, at times been partial and fragmented, usually because outsourcing has not been the primary focus of the research, but rather, only one element of some other investigation such as school responses to governmental inquiries or teacher' perceptions of the learning area (e.g. Lynch 2007; Webster 2001). Even within commentaries, it is seldom the primary concern, instead being something to which passing reference is made (e.g. Davis 2006). Adding to this state of affairs is the fact that the two sources of arguably the more rigorously collected data are unpublished doctoral dissertations (Ardzejewska 2009; Webster 2001).

Yet there are, perhaps now more than ever, good grounds for redressing this state of affairs. Recent research on the privatisation of education has demonstrated that the ways in which schools and schooling are being conceived of, constructed and conducted are undergoing significant change (e.g. Apple 2006; Ball 2007; Burch 2009). Chief among these have been an increasing commercialisation, commodification and marketisation of educational services and a proliferation of extra-educational interest groups seeking a stake in the development and delivery of these services. 
To be sure, educational institutions have not escaped the tentacles of what Sennett (1998) has dubbed 'flexible capitalism'. Furthermore, as noted above, there is some, albeit limited evidence that HSPE work has not been immune to these trends. It has been shown that some primary schools readily outsource HSPE work (see Lavin, Swindlehurst, and Foster 2008; Webster 2001) and that HSPE work is more susceptible to outsourcing in such primary schools than other learning areas (see Ardzejewska 2009). Moreover, it has not been a phenomenon peculiar to any one location. In commentaries, the outsourcing of HSPE work has been noted in Australia, New Zealand and England among others (e.g. Blair and Capel 2008; Davis 2006; Griggs 2008; Kirk 2009; Macdonald, Hay and Williams 2008). Thus it would seem, as Tinning $(1992,26)$ cautioned nearly two decades ago, that 'it really is time that those of us who define ourselves as physical educators take seriously the trends and changes which are currently impacting on our professional work'.

The purpose of this paper is to (belatedly) contribute to this challenge by investigating the outsourcing of HSPE work in the Australian state of Queensland. Specifically, we examine the prevalence of such work being outsourced by Queensland schools, the ways that these schools are using such services, and the reasons why they have done so. On the basis of the data presented, we will argue that the outsourcing of HSPE work is a widespread practice among the schools studied and that in the current social, political and economic climate, it is a practice with the potential to significantly disturb work, learning and the politics of expertise (Seddon, Henriksson and Niemeyer 2010) in the context of health, sport and physical education. In so doing, our argument will draw on PE research, as well as sociological writing and research on education, work and occupations, more generally. 


\section{What is outsourcing?}

Outsourcing can be defined as the state or process of procuring goods and services from external suppliers (Mol 2007). In this way, it is a phenomenon that is identifiable first and foremost according to a location or source sensitivity (Ritzer and Lair 2007). Beyond this, as Davis-Blake and Broschak (2009) have argued, outsourcing is a multi-dimensional and heterogeneous practice that varies in its complexity on the basis of: the range of goods and services outsourced; the amount of control exercised by an outsourcer over a supplier; the embeddedness of the social relationship between outsourcer and supplier; and, the level of formality governing the outsourcing arrangement.

Outsourcing arrangements covering the full gamut of this complexity are the focus of this research. Queensland schools are the outsourcers examined and HSPE work is the outsourced service in question. As the data presented herein demonstrate, the external suppliers to whom HSPE work is outsourced are many and varied. They include, among others, sporting organisations and health agencies, as well as commercial and non-commercial fitness, dance, swimming and outdoor adventure centres. In this way, the outsourcing of HSPE work is a practice that 're-agents' (Jones 2003) education, or, as Ball $(2007,16)$ has put it, inserts 'new players into the field of ... education service delivery'.

\section{Research context}

One of the characteristic features of the Queensland primary and secondary school context is the predominance of the role of the specialist HPE teacher (Ministerial Review Committee for School Sport and Physical Activity 2007). This role positions its incumbent as the primary performer of HSPE work in the school. As outlined below, this contextual feature is a significant point of difference from those contexts in which previous outsourcing research has been conducted. Additionally, there is a 
formal requirement that all graduates from primary school teacher education programs are able to teach HPE, not just those who graduate from Physical Education Teacher Education (PETE) programs (Queensland College of Teachers 2009).

HSPE work in Queensland schools is performed in a number of educational ‘times and spaces' (i.e. Key Learning Area $[\mathrm{KLA}]^{2}$, subject, program or activity) ${ }^{3}$. During the compulsory years of schooling, all students are mandatorily exposed to HSPE work in curriculum time through the HPE KLA. During the post-compulsory years of schooling, students can elect to study the subjects Physical Education (PE), Health Education (HE) and Recreation, each of which also exposes students to HSPE work during curriculum time. Outside of curriculum time, Queensland students are exposed to HSPE work in extra-curricular activities throughout their years at school. Whereas the delivery of HPE, PE, HE and Recreation are guided by syllabus documents and therefore relatively standardised, the quantity and quality of HSPE work performed outside of the curriculum varies from school to school. In Queensland outdoor adventure activities are not delivered through a stand-alone subject. Instead, HSPE work relating to these activities occurs through any or all of the five educational times and spaces just described. However, in this study outdoor adventure activities are treated analytically as a distinct entity. This is because of the uniqueness of these activities and the environments in which they are undertaken.

Queensland schools have a significant amount of authority to manage their own operations, albeit within a number of centrally determined frameworks. For example, syllabuses in Queensland are what has been termed 'low definition' and thus provide schools with the flexibility 'to plan their curriculum and assessment in ways that best suit their individual contexts' (Queensland Studies Authority n.d.). This autonomy includes the freedom to choose the physical activities they will incorporate 
into their curricula and extra-curricular programs (e.g. Queensland Studies Authority 2010). Importantly, what we refer to here as the outsourcing of HSPE work is also both permitted and regulated in a similar fashion (e.g. Queensland Department of Education 2009).

\section{New 'players': Previous research on the outsourcing of HSPE work}

Published data (as opposed to commentaries or unpublished findings) on the outsourcing of HSPE work is limited in both quantity and in scope. To the best of our knowledge, all previously reported data (in English) have been collected in primary schools. Furthermore, these primary schools have been in education systems where the responsibility for performing HSPE work (and indeed, educational work related to each of the other learning areas as well) has primarily been assigned to the role of classroom generalist teacher.

Where it has been collected, prevalence data has demonstrated that the outsourcing of HSPE work in such schooling contexts is widespread. In Webster's (2001) unpublished survey of 227 New South Wales (NSW) classroom generalist teachers from 37 primary schools, $65 \%$ indicated that they had outsourced some form of HSPE work in the previous 12 months. Similarly, 62\% of the 401 NSW primary school principals surveyed in Ardzejewska's (2009) unpublished study stated that they had outsourced some form of educational work in their school. Of these instances of outsourcing, $73 \%$ related to curricular or extra-curricular health, sport or physical education. Finally, in a survey of 125 primary schools in North West England, Lavin and colleagues (2008) found that $86 \%$ were outsourcing some form of curricular HSPE work.

Data on the ways that primary schools have used outsourced HSPE work and the reasons why they have done so have also been consistent. The most commonly 
outsourced work reported in this body of published and unpublished literature relates to traditional sports, gymnastics, dance, and swimming (Ardzejewska 2009; Evans 1993; Lavin et al. 2008; Webster 2001). Five reasons for outsourcing HSPE work are frequently reported. The first is to access the external suppliers' equipment or facilities (Ardzejewska 2009; Evans 1993). The second is to access the external suppliers' specific expertise (Ardzejewska 2009; Evans 1993; Webster 2001). The third is to use the outsourced HSPE work as a form of professional development where teachers observe the work performed by the supplier (Ardzejewska 2009; Evans 1993; Lavin et al. 2008). The fourth is to provide students with experiences that they would not otherwise have received (Ardzejewska 2009). The final reason is to increase student motivation by exposing them to the perceived passion, enthusiasm and expertise of the external supplier (Ardzejewska 2009; Evans 1993).

Two studies have examined schools' reasons for not outsourcing HSPE work. Ardzejewska's (2009) participants reported prohibitive financial costs, timetabling difficulties, supplier unavailability, small student populations, a lack of physical resources and geographical isolation as significant hindrances to the outsourcing of HSPE work. Similarly, Clough and Trail (1992) also found geographical isolation to be a barrier.

Only Webster (2001) has examined the prevalence of fee-based outsourcing arrangements. Forty-five percent of Webster's $(2001,152)$ respondents 'indicated that their students paid a fee for such instruction'. These fees ranged between $A \$ 1$ and A $\$ 5$ per student per session. In his investigation of 23 sports coaches to whom HSPE work was being outsourcing in the English West Midlands, Griggs (2010) reported costs charged to schools of $£ 20$ per class per hour, but did not report on how many schools were doing so or how such costs were being paid for. 
The research presented in this paper extends previous examinations of HSPE work outsourcing in four important ways. First, whereas previous studies have concentrated exclusively on primary schools, the data presented below have been collected in both primary and secondary schools. Thus, it provides an insight into whether the idiosyncrasies of the primary or secondary schooling contexts have any bearing on the prevalence of outsourcing, the services outsourced or the fees involved in these arrangements and their payment. Second, unlike previous studies this research presents data on outsourcing in an education system characterised by the predominance of the role of the specialist primary school HPE teacher. Therefore, the data that follow provide an opportunity to ascertain what, if any, effect the role of the specialist has on outsourcing behaviours in primary school settings. Third, it pays closer attention than previous investigations to the prevalence of fee-based outsourcing arrangements by focusing on the source of the funds used to pay these fees and by reporting these behaviours using the school as the unit of analysis. Fourth, in our discussion of the data presented and their significance, we endeavour to make stronger connections between specific outsourcing practices in schools and the broader social, political and economic contexts in which they are set than has been the case in much of the previous research and commentary.

\section{Methods}

\section{Participants}

The sample unit used in this study was the school. Our sample included 846 schools from across the Queensland education system. Initially, our intention had been to survey all 1,713 Queensland schools. However, despite having permission to approach all non-government schools, the Queensland Department of Education did not give us access to all government schools. Therefore, our sample population 
comprised all non-government schools $(n=446)$ and an agreed sample of 400 government schools. All non-government schools were included because Queensland Department of Education research approval was contingent on not making comparisons between government and non-government schools. Thus, by keeping the number of government and non-government schools relatively equal, we attempted to control for any influence that this variable may have had on the data collected. Our sample of 400 government schools was generated using proportionate random stratification (Hedges 2004). Location, student population and school type were the factors used to stratify the sample (see Table 1). However, the sample was stratified according to the factor proportions of all Queensland schools rather than just the government schools. We did this to maintain the representativeness of the sample in relation to those factors we were permitted to compare.

\section{Questionnaire}

This research was descriptive in nature. Accordingly, the aim of the questionnaire used was to collect profile data on the outsourcing of HSPE work. The questionnaire consisted of 21 items, three of which were administrative, eight of which were about school and respondent demographics, and ten of which focused on how and why schools had or had not outsourced HSPE work over the previous 12 months. Specifically, these ten items were about outsourcing practices in each of the six educational times and spaces described above. Six items were open-ended and fifteen were closed or pre-coded. We developed the questionnaire on the basis of our combined experiences as researchers and HPE teachers. We then piloted the mail and Internet versions of the questionnaire with a group of five teachers from schools within the sample population. This group consisted of one principal, two Heads of Department, and two HPE teachers. We attempted to make both versions of the 
questionnaire appear as similar as possible to minimise mode difference error (Dillman, Smyth and Christian 2009). After conducting the pilot test, we informally interviewed each pilot test participant to gauge the questionnaire's face and content validity.

\section{Procedure}

Data were collected over a three-month period using a mixed-mode design (Dillman et al. 2009). After receiving research approval from the relevant school authorities, an information email containing a link to the Internet questionnaire was sent to each principal of the schools in the sample population. The Internet survey company SurveyMonkey hosted the questionnaire and provided the tools used for its construction. Each principal was invited to complete the questionnaire (in consultation with other staff if required) or to forward it on to be completed by a better-informed member of staff. An incentive was offered to all participants, consisting of entry into a prize draw for a $\$ 300$ sport equipment or clothing voucher to be awarded to one of the responding schools. A reminder email also containing a hyperlink to the questionnaire was sent two weeks later to those schools that had not yet completed it. The Internet questionnaire closed one week after this reminder email. The mail questionnaire was then sent to those schools that had not completed the Internet version or responded to our electronic invitations. We included a reply-paid envelope and an information letter with the mail survey. This information letter contained the same information, instructions and layout as our initial email, including advertisement of the incentive.

\section{Data analysis}

The data obtained from the questionnaire's pre-coded items were categorical in nature. Those data collected through the open-ended items were content analysed and the frequencies noted. This process of analysis involved the coding of the raw data 
and then the organisation of these data codes into code themes. It was the frequency of these code themes that is presented here. The first author, in consultation with the second and third authors, performed all processes of data collation, cleaning and coding. Simple relational analyses of the data (Sarantakos 2005) were calculated and presented below.

\section{Results}

Thirty-two percent ( $\mathrm{n}=271$ ) of the sample population completed a questionnaire. The respondents were largely representative of the sample according to each of the stratification factors used (see Table 1). Fifty-seven percent $(n=154)$ of respondents completed the Internet questionnaire. The remaining 47\% $(n=117)$ completed the mail questionnaire. Item response rates ranged between $87 \%(\mathrm{n}=236)$ and $100 \%$ depending on the item in question.

[Table 1 near here]

Figure 1 demonstrates that the outsourcing of HSPE work was commonplace in Queensland schools. Eighty-five percent $(n=230)$ of schools reported outsourcing some form of HSPE work in the previous twelve months. This percentage was relatively consistent when HSPE work outsourcing was measured in relation to school type, location, student enrolment, and the number of specialist HPE teachers appointed to the school. Special schools were one exception to this, however, with so few special schools having responded, it is difficult to draw any inferences about the outsourcing of HSPE work in these schools.

[Figure 1 near here]

Of those schools that outsourced HSPE work, $87 \%(n=200)$ had done so in one, two or three of the educational times and spaces examined (i.e. HPE, PE, HE, Recreation, extra-curricular activities, and outdoor adventure activities). Of the 
remaining $13 \%, 9 \%(n=20)$ and $4 \%(n=9)$ respectively had outsourced HSPE work in four and five of the measured times and spaces. Only one school outsourced educational work in all six of the investigated times and spaces.

Figure 2 indicates that more schools used outsourced HSPE work for outdoor adventure activities and extra-curricular activities than for HPE, PE, HE and Recreation. The data here for PE, HE and Recreation have been expressed as a percentage of responding schools offering these subjects due to their status as elective subjects within secondary schools.

[Figure 2 near here]

Qualitative content analysis of the instructional services outsourced yielded 45 code categories. The ten code categories with the highest frequency counts are included in Table 2. This list of outsourced educational services consists of a wide range of those physical cultural forms that Kirk (2009) has argued influence the construction of PE. It also demonstrates that very few schools outsourced educational work related to 'sport and exercise science' and 'health'.

[Table 2 near here]

Seventy-five percent $(n=203)$ of all responding schools indicated that they engaged in fee-based HSPE work outsourcing arrangements in the previous twelve months. Furthermore, $83 \%$ of all outsourced HSPE work was provided in exchange for money. This percentage was highest in Recreation (100\%) and lowest in HE (78\%). Figure 3 demonstrates that the majority of schools pay for outsourced HSPE work using school funds or by charging participating students and that few schools use funds from other sources. Figure 3 also shows that comparatively fewer schools subsidise outsourced educational work for outdoor adventure activities than for HPE, PE, HE, Recreation and extra-curricular activities. 
[Figure 3 near here]

Qualitative content analysis of schools' reasons for outsourcing HSPE work yielded 27 code themes. Identical analysis of schools' reasons for not outsourcing HSPE work yielded nine code themes. Table 3 summarises these findings. Overwhelmingly, the most frequently reported reason for using outsourced HSPE work was to access the external suppliers' expertise. The most frequently reported reason for not outsourcing HSPE work was that existing school staff had adequate expertise. The second most frequently reported reason for not outsourcing HSPE work was the inability to afford it.

[Table 3 near here]

\section{Discussion}

The purpose of this research was to investigate the outsourcing of HSPE work in Queensland schools by examining the prevalence of such outsourcing, the ways that schools are using it, and the reasons why they have done so. In short, it aimed to capture one particular outsourcing 'state of play', or to conduct what Mol (2007) has termed a 'static analysis' of outsourcing. In this section, we discuss the significance of these data in relation to previous research on the outsourcing of HSPE work and the broader social, political and economic contexts in which such practices are set.

On the basis of previous studies and the data presented above, it would appear that neither the prevalence of HSPE work outsourcing nor the type of work outsourced is related to the organisational role of the primary school HPE specialist teacher. Approximately $84 \%(n=123)$ of all responding Queensland primary schools reported outsourcing HSPE work in the year prior to being surveyed. This figure accords with the high prevalences observed in the primary schooling systems without HPE specialists by Ardzejewska (2009), Lavin and colleagues (2008) and Webster 
(2001). Furthermore, with respect to the types of HSPE work outsourced, the outsourcing by Queensland primary schools of that related to traditional games and sports within the curriculum is consistent with the outsourcing practices of those primary schools researched elsewhere in both Australia and England (see Ardzejewska 2009; Evans 1993; Lavin et al. 2008; Webster 2001). In the absence of comparable data, such comparisons cannot be made between the prevalence and types of outsourcing in Queensland secondary education and that of elsewhere. To this end, the data presented here constitute a point of reference for future investigations of outsourcing in secondary school contexts.

Notwithstanding their dynamic and interrelated nature, it is instructive to consider the outsourcing of HSPE work across both the primary and secondary education contexts in terms of supply and demand. To do so, is to think about the state of play on each side of the organisational boundary, for the both the schools themselves and those entities willing and able to provide them with outsourced educational work.

On the demand side of the equation, the frequency with which sports, games, swimming and gymnastics were outsourced both here and elsewhere could be considered indicative of a 'business as usual' approach to the content of HSPE work. As Kirk (1992; 1998; 2009) among others has demonstrated, these activities are dominant features of past and present constructions of health, sport and physical education in those contexts where HSPE work outsourcing has been examined. Thus, there is some evidence here to implicate the outsourcing of HSPE work in the reproduction of the status quo with respect to the constitution of health, sport and physical education in Queensland. That said, decisions to outsource often marginalised content such as outdoor adventure activities, dance, and martial and 
meditative arts, may be reflective of attempts by school-based curricular and extracurricular program developers to challenge the dominant focus of HSPE work. Ascertaining whether this is the case is an empirical matter that would require further examination of the motives underpinning schools' decisions to outsource and the symbolic value attached to both the outsourced and non-outsourced work by all those stakeholders involved.

In this respect, it is interesting to look at respondents' uses of outsourced HSPE work across different educational times and spaces. Figure 2, for example, shows that in relative terms, HSPE work was outsourced more frequently in outdoor adventure settings and for extra-curricular purposes than during curriculum time and in the curricular spaces of HPE, PE HE or Recreation. To be sure, this may be a reflection of supply. That is, it may be reflective of that which is on offer from prospective suppliers of outsourced HSPE work. However, it is also possible that it indicates an active choosing by school-based decision makers that is underpinned by a distinction between times and spaces that are more central than others to the educational mission of the school and/or to teachers' work. If this were the case, it would be fascinating to know just who is making the distinction between core and peripheral tasks, on what basis they are doing so and to what professional and educational effect. For example, what issues might the outsourcing of extra-curricular work present for those teachers who find such work professionally rewarding and supportive of their curricular work (see O'Connor and Macdonald 2002)?

Table 3 also provides a curious insight into the nature of the demand for outsourced HSPE work. The majority (51\%) of all those schools that engaged in some form of HSPE work outsourcing did so to access the expertise of external suppliers. Again, this is a finding that mirrors that found in previous studies (see Ardzejewska 
2009; Evans 1993; Webster 2001), and, again it is a finding that demonstrates that outsourcing is not a practice unique to schools without HPE specialist teachers.

Considered in conjunction with those activities that were most frequently outsourced, this might lead some to consider these data symptomatic of problems within physical education teacher education (PETE). Siedentop $(2002,368)$, for example, has argued that contemporary PETE has retreated from sport performance in such a way as to have 'virtually eliminated the possibility of developing a serious body of pedagogical content knowledge for teaching physical education'. Similarly, the preparation of teachers for outdoor education and adventure has been virtually eliminated from Australian PETE. Thus, the outsourcing of HSPE work could be understood, in large part, as a strategy deployed within schools to compensate for insufficient levels of particular kinds of expertise related to HSPE work.

However, all of this presupposes that the notion of expertise itself is consistent and transparent. Thus, there may also be much more to this finding than the idiosyncrasies of HPE teacher preparation. One might also speculate a connection here to a broader politics of expertise that works to manufacture demand. From such a perspective, the notion of expertise itself is interrogated - what constitutes expertise in any given situation, what factors influence its constitution, whose interests are and are not served by these processes of constitution and their effects (particularly in relation to the value of professional knowledge)? Gaining this sort of insight into the place of expertise and its politics in the demand for outsourced HSPE work is, therefore, another important avenue for future research on outsourcing.

On the supply side of the equation, that $85 \%(n=230)$ of the schools surveyed in this study engaged in HSPE work outsourcing, indicates a relatively widespread availability of services from external providers. As has already been alluded to, the 
outsourcing of HSPE work is not a practice that takes place in a social, political or economic vacuum. Thus, any satisfactory attempt to account for the prevalence of supply must continue a task begun by Macdonald, Hay and Williams (2008) and pay attention to contemporary relations between capital, education and the state; or, more specifically, 'on the structural coupling and co-evolution of accumulation regimes and political regimes and how this is influenced by the attempts of different social forces to steer their individual and/or conjoint development' (Jessop 2002, 3).

Following Ball (2007), we argue that the emergence of an education services industry (ESI) - to which suppliers of outsourced educational work belong - is part of the shift from what Jessop (2002) has termed the Keynesian National Welfare State (KNWS) towards the Schumpeterian Workfare State (SWS). There are at least three interrelated ways in which we suggest this shift has influenced the state of affairs presented here. The first is the SWS's facilitative role as a 'commodifying agent' (Cerny 1990) that re-works education into outsourceable forms and that permits and legitimates the use of entrepreneurial forms of outsourced educational work (Ball 2007). Indeed, policy evidence of the latter was highlighted in a previous section. The second is the SWS's facilitative role in 'endogenously privatising' (Hatcher 2000) education such that schools are directly and indirectly prompted to 'act as though they were businesses, both in relation to clients and workers' (Ball 2007, 14). In this way, it could be considered relatively unsurprising that a practice so pervasive in postFordist economies (Mol 2007) should become a feature of 'new education in new times' (Kenway et al. 1994). The third is the SWS's role in promoting, encouraging and engaging in the pursuit of non-educational goals and agendas through schools, such as those related to the development of a healthy and physically active citizenry. All three of these are features of the re-articulation and re-scaling involved in the 
political and economic transformation postulated by Jessop. Furthermore, all three have had the net effect of creating and fostering new 'markets' into which the ESI can enter.

Turning to those entities comprising that fraction of the ESI related to HSPE work, the raw data from which Table 2 was constructed show that it is not merely factors of demand that are implicated in the reproduction of the status quo. For example, the 92 descriptions of outsourced HSPE work that were categorised as 'Australian football', 'Cricket' or 'Rugby league', were almost solely comprised of programs funded, developed and delivered by these sports' state and national organisations. Large-scale operations such as these aimed at gaining and maintaining a presence in schools through outsourced HSPE work require the ability to trade on significant levels of not just economic but also cultural capital. The possession of such resources, and the way they influence who can and cannot afford to enter outsourcing markets as external suppliers, would seem to be an important factor when thinking about the nature of outsourcing and its impact on the constitution of health, sport and physical education.

In light of such substantial use of outsourced HSPE work, it is important to consider the effect it may have on the locus of control and the designation of accountability related to health, sport and physical education. It is well acknowledged in the field of management studies that outsourcing is a practice that has the potential to create issues related to the control and coordination of the outsourced tasks (Mol 2007). In the PE context, Kirk (2002) has acknowledged precisely this point by arguing that inter-organisational arrangements such as partnerships multiply the interests and agendas in play as well as the possibility that these interests and agendas will come into conflict. It is possible that an acknowledgement of this issue is implicit 
in the finding reported here that very few schools outsourced HSPE work across more than three of the educational times and spaces examined.

The notion of control in any outsourcing arrangement also has - and this is particularly important in the neoliberal educational context - important implications for processes of accountability. Thus, in relation to the services provided by external suppliers, one might reasonably ask who is accountable for what, how and to whom are they held accountable, and to what effect? Given that all outsourcing arrangements, by definition, involve the transfer of some degree of control outside the school, and given the pervasiveness of accountability mechanisms within contemporary systems of education (Ranson 2003), such questions are significant indeed, not only at an operational level, but also with respect to the notion of a free and democratic education.

Beyond those aspects of supply and demand examined above, one final feature of these data and their relations to both previous research and broader social, political and economic processes shall be addressed. This concerns the data depicted in Figure 3. It is not possible to discern the prevalence of fee-based outsourcing arrangements among schools in Webster's NSW primary school study. Therefore, to the best of our knowledge, there is no point of reference against which the figures observed here can be compared. That said, this figure and Webster's (2001) are still significant, particularly in the way they indicate the treatment of HSPE work and knowledge as commodities and the insertion of commerce into the classroom (Ball 2004).

The risk in fee-based outsourcing is that the value of HSPE work and knowledge as objects of exchange will come to dominate their values in and of use. One corollary of this is an unequal distribution of access to certain kinds of HSPE work and knowledge according to a school or a student's ability to pay (see Table 2 
and the review of literature above). Furthermore, as Ball and Youdell (2008) have forcefully argued, such treatments of educational services in the context of competitive schooling markets transform the educational identities of principals, teachers, parents and students into those of managers, technicians, clients and outputs. Moreover, they contend that there is the also a tendency in post-Fordist societies for such commodification to potentiate transformed labour relations through 'individualised contracts, performance-related pay, flexible contracts and the mix of qualified and other teaching personnel' (Ball and Youdell 2008, 92). In all of this, knowledge itself is 'produced in order to be sold' and 'consumed in order to be valorised in a new production' (Lyotard 1984, 4). And so, to return to a previous point, it is in this context that Ball (2004) has argued one can understand the explosion of 'knowledge for schooling' of which extensive supply of outsourced HSPE work is but one example.

The high prevalence of fee-based arrangements observed here should also prompt questions about the sustainability of outsourced HSPE work. Outsourcing arrangements that expose educational work to 'market forces', by definition, involve 'market consequences', both good and bad. Such negative 'market consequences' have become evermore salient in the wake of the Global Financial Crisis as consumers and businesses in many parts of the world deal with economic downturn and governments mobilise austerity measures. Thus, when or if buyers and sellers of outsourced HSPE work, or perhaps their subsidisers (e.g. the state), decide that their financial resources are best directed elsewhere, health, sport and physical education in outsourcing schools might prove difficult to sustain. In such instances, the sustainability of health, sport and physical education post-outsourcing is likely to be significantly determined by the relative dependency that the outsourcer had on the 
services outsourced (Vincent 2005), the range of activities outsourced and the embeddedness of the social relationship between outsourcer and supplier (DavisBlake and Broschak 2009). In relation to future research, this points to the importance of investigating not only the number of outsourcing arrangements that schools engage in, but also the ways in which schools embed any form of outsourced educational work into their educational operations.

\section{Conclusion}

In the absence any substantial body of empirical research on what has been acknowledged by many as an important professional and educational issue (e.g. Hoffman 1987; Kirk 2009; Tinning 1992), this paper sought to investigate the outsourcing of HSPE work in educational settings that had hitherto been unexamined (i.e. secondary schools and primary schools with specialist HPE teaching roles).

In so doing, it replicated a number of the findings of those who have collected data on outsourcing in primary schools where HSPE work has been a responsibility primarily allocated to the role of the classroom generalist teacher. To this extent, it has demonstrated, albeit only within one such education system, that high levels of outsourcing of relatively traditional forms of HSPE work and the rationales that underpin them are not practices peculiar to those initial research contexts. Furthermore, it has attempted to deepen scholarly understanding of HSPE work outsourcing by investigating the distribution of outsourcing across HSPE times and spaces, as well as the prevalence of fee-based outsourcing arrangements and the distribution of those sources used to make these payments. Finally, it has also strived to make explicit connections between health, sport and physical education practices in schools and broader social, political and economic transformations. 
In this respect, this paper is intended as a starting point. It has provided a static analysis of outsourcing (Mol 2007) that was intended to be 'extensive' rather than 'intensive'. The data provide an insight into an important but as yet under-researched phenomenon, and serve as a stimulus for prompting critical questions about the politics of educational expertise, accountability for and control of educational services, and the professional and educational effects of changing divisions of educational labour. These are the kind of questions hinted at by the likes of Tinning (1992), Hoffman (1987) and Kirk (2009); questions that 'concern what kind of future we want for education and what role privatisation and the private sector might have in the future, and crucially how justice and ethical behaviour can be balanced against a necessary pragmatism within a modern and democratic system of education' (Ball 2007, 191).

The expansion of flexible capitalism and the consolidation of the global neoliberal project are disturbing traditional patterns of work and organisation across a range of different countries and occupations (Seddon et al. 2010). As one example of these disturbances, outsourcing has been shown to blur organisational boundaries, fragment work and produce hybrid organisational forms (Grimshaw et al. 2005). Thus, it is a form of both creation and destruction (Ritzer and Lair 2007), with the potential to produce new types of HSPE work and HSPE workers, as well as to transform and/or replace those that preceded them. To this end, it is a feature of contemporary practice to which physical educators must pay due attention as possible PE futures become present PE realities.

\section{Notes}

1. Here, the term HSPE work is being used to refer to the human labour inherent in the intentional efforts of teachers, coaches and the like, to facilitate the learning of those in their charge as it relates to health, physical activity and the body. 
2. 'KLAs are the eight nationally agreed learning areas that form the common curriculum for the compulsory years of schooling (Prep to Year 10). These are: The Arts, English, Health and Physical Education, Languages other than English, Mathematics, Science, Studies of Society and Environment, and Technology.' (Queensland Studies Authority n.d., 13)

3. We acknowledge that educational work related to health, physical activity or the body may be performed in school 'times and spaces' other than those focused on here (e.g. learning about energy production in biology). However, for the purposes of highlighting the potential impact of outsourcing on the health and physical education teaching profession, we have restricted our investigation to those educational times and spaces it is primarily responsible for.

\section{References}

Apple, M. W. 2006. Educating the 'right' way: Markets, standards, God, and inequality. London: Routledge.

Ardzejewska, K. 2009. Managing the Delivery of Subjects in NSW Government Primary Schools: Using PE 'Specialists'. PhD diss., Macquarie University.

Ball, S. J. 2004. Education for sale! The commodification of everything? Presented as the King's Annual Education Lecture at University of London, June 17, in London, England.

Ball, S. J. 2007. Education plc: Understanding private sector participation in public sector education. London: Routledge.

Ball, S. J. and D. Youdell. 2008. Hidden privatisation in public education. Brussels: Education International.

Blair, R. and S. Capel. 2008. The use of coaches in primary physical education to cover planning, preparation and assessment time - some issues. Physical Education Matters Summer: 9-11.

Burch, P. 2009. Hidden markets: The new education privatization. London: Routledge.

Cerny, P. 1990. The changing architecture of politics: Structure, agency and the future of the State. London: Sage.

Clough, J., and R. D. Trail. 1992. The 1991 report on Aussie Sport, and Sport for Kids Research. Canberra: Australian Sports Commission.

Davis, R. 2006. Physical education: The state of play. ACHPER Healthy Lifestyles Journal 53, no. 1: 12-16.

Davis-Blake, A., and J. P. Broschak. 2009. Outsourcing and the changing nature of work. Annual Review of Sociology 35: 321-340.

Dillman, D. A., J. D. Smyth, and L. M. Christian. 2009. Internet, mail, and mixedmode surveys: The tailored design method. Hoboken: John Wiley \& Sons.

Evans, J. 1993. The role of Sport Development Officers in the sport education of teachers. The ACHPER National Journal Summer: 10-15.

Griggs, G. 2008. Outsiders inside: The use of sports coaches in primary schools. Physical Education Matters Spring: 33-36.

Griggs, G. 2010. For sale - primary school physical education. $£ 20$ per hour or nearest offer. Education 3-13 38: 39-46.

Grimshaw, D., M. Marchington, J. Rubery, and H. Willmott. 2005. Introduction: Fragmenting work across organizational boundaries. In Fragmenting work: Blurring boundaries and disordering hierarchies, ed. M. Marchington, D. Grimshaw, J. Rubery and H. Willmott, 1-31. Oxford: Oxford University Press. 
Hatcher, R. 2000. Profit and power: Business and Education Action Zones. Education Review 13: 71-77.

Hedges, B. 2004. Sampling. In Social research methods: A reader, ed. C. Searle, 6372. London: Routledge.

Hoffman, S. J. 1987. Dreaming the impossible dream: The decline and fall of physical education. In Trends toward the future in physical education, ed. J. D. Massengale, 121-135. Champaign: Human Kinetics.

Jessop, B. 2002. The future of the capitalist state. Cambridge: Polity Press.

Jones, K. 2003. Education in Britain: 1944 to the present. Cambridge: Polity Press.

Kenway, J., C. Bigum, L. Fitzclarence, J. Collier, and K. Tregenza. 1994. New education in new times. Journal of Education Policy 9: 317-333.

Kirk, D. 1992. Defining physical education: The social construction of a school subject in postwar Britain. London: The Falmer Press.

Kirk, D. 1998. Schooling bodies: School practice and public discourse 1880-1950. London: Leicester University Press.

Kirk, D. 2002. Quality physical education, partnerships and multiple agendas: A response to Karel J van Deventer. Paper presented at the 12th Commonwealth International Sport Conference, July 19, in Manchester, England.

Kirk, D. 2009. Physical education futures. London: Routledge.

Lavin, J., G. Swindlehurst, et al. 2008. The use of coaches, adults supporting learning and teaching assistants in the teaching of physical education in the primary school. Physical Education Matters Spring: ix-xi.

Lynch, T. (2007). What has changed since the 1992 Senate Inquiry into Physical and Sport Education? An evaluation of school responses within three Brisbane Catholic Education (BCE) primary schools. ACHPER Healthy Lifestyles Journal 54, no. 1: 16-23.

Lyotard, J.-F. 1984. The postmodern condition: A report on knowledge. Trans. G. Bennington and B. Massumi. Minneapolis, University of Minneapolis Press.

Macdonald, D., P. Hay, and B. Williams. 2008. Should you buy? Neo-liberalism, neoHPE, and your neo-job. New Zealand Physical Educator 41, no. 3: 6-13.

Ministerial Review Committee for School Sport and Physical Activity. 2007. Review report: Future development of school sport and physical activity. Brisbane: Department of Education, Training and the Arts.

Mol, M. J. 2007. Outsourcing: Design, process, and performance. Cambridge: Cambridge University Press.

O'Connor, A. and D. Macdonald. 2002. Up close and personal on physical education teachers' identity: Is conflict an issue? Sport, Education and Society, vol 7: 37-54.

Queensland College of Teachers. 2009. Program approval guidelines for preservice teacher education. Brisbane: Queensland College of Teachers.

Queensland Department of Education. 2009. SCM-PR-010: External Programs Presented in State Schools. http://education.qld.gov.au/strategic/eppr/schools/scmpr010/

Queensland Studies Authority. 2010. Physical Education: Senior Syllabus 2010. Brisbane: Queensland Studies Authority.

Queensland Studies Authority. n.d. Learning P-12: Informed prescription, informed professionalism. Brisbane: Queensland Studies Authority.

Ranson, S. 2003. Public accountability in the age of neo-liberal governance. Journal of Education Policy 18: 459-480. 
Ritzer, G. and C. Lair. 2007. Outsourcing: Globalization and beyond. In The Blackwell Companion to Globalization, ed. G. Ritzer, 307-329. Malden: Blackwell

Sarantakos, S. 2005. Social research. New York: Palgrave Macmillan.

Seddon, T., L. Hendriksson and B. Niemeyer. 2010. Introduction - disturbing work and transforming politics. In Learning and work and the politics or working life: Global transformations and collective identities in teaching, nursing and social work, ed. T. Seddon, L. Hendriksson and B. Niemeyer, 1-15, London: Routledge.

Sennett, R. 1998. The corrosion of character: The personal consequences of work in the New Capitalism. New York: Norton.

Siedentop, D. 2002. Content knowledge for physical education. Journal of Teaching in Physical Education 21: 368-377.

Tinning, R. 1992. On speeches, dreams, and realities: Physical education in the year 2001. The ACHPER National Journal Summer: 24-26.

Vincent, S. 2005. Really dealing: A critical perspective on inter-organizational exchange networks. Work, Employment and Society 19: 47-65.

Webster, P. J. 2001. Teachers' Perceptions of Physical Education within the K-6 Personal Development, Health and Physical Education Key Learning Area. PhD diss., The University of Wollongong. 
Table 1. Demographics of research population, sample and respondents.

\begin{tabular}{llrrrrrr}
\hline & & \multicolumn{2}{c}{ Population } & \multicolumn{2}{c}{ Sample } & \multicolumn{2}{c}{ Respondents } \\
& & $\mathrm{n}$ & $\%$ & $\mathrm{n}$ & $\%$ & $\mathrm{n}$ & $\%$ \\
\hline Sector & Government & 1245 & 73 & 400 & 47 & 106 & 39 \\
& Independent & 181 & 10 & 162 & 19 & 56 & 21 \\
& Catholic & 287 & 17 & 284 & 34 & 109 & 40 \\
& Total & 1713 & 100 & 846 & 100 & 271 & 100 \\
\hline Type & Primary & 1159 & 68 & 520 & 62 & 146 & 54 \\
& Secondary & 256 & 15 & 128 & 15 & 58 & 21 \\
& Combined & 250 & 14 & 181 & 21 & 64 & 24 \\
& Special & 48 & 3 & 17 & 2 & 3 & 1 \\
& Total & 1713 & 100 & 846 & 100 & 271 & 100 \\
\hline Location & Metropolitan & 798 & 47 & 434 & 51 & 139 & 51 \\
& Provincial & 180 & 10 & 103 & 12 & 43 & 16 \\
& Rural & 554 & 33 & 238 & 28 & 62 & 23 \\
& Remote & 181 & 10 & 71 & 9 & 27 & 10 \\
& Total & 1713 & 100 & 846 & 100 & 271 & 100 \\
\hline Enrolment & $1-250$ & 785 & 46 & 275 & 33 & 85 & 32 \\
(Students) & $251-500$ & 369 & 21 & 270 & 32 & 67 & 25 \\
& $501-1000$ & 403 & 24 & 213 & 25 & 77 & 28 \\
& $1001-1500$ & 121 & 7 & 70 & 8 & 33 & 12 \\
& $1501+$ & 35 & 2 & 18 & 2 & 9 & 3 \\
& Total & 1713 & 100 & 846 & 100 & 271 & 100 \\
\hline
\end{tabular}


Table 2. Ten most frequently outsourced HSPE services.

\begin{tabular}{lr}
\hline Code theme & $\mathrm{n}$ \\
\hline Outdoor adventure activities & 83 \\
Minor games and modified sports & 61 \\
Australian football & 52 \\
Swimming and aquatics & 31 \\
Dance & 24 \\
Fitness & 23 \\
Rugby league & 22 \\
Gymnastics & 19 \\
Cricket & 18 \\
Meditative and martial arts & 15 \\
\hline
\end{tabular}


Table 3. Five most frequent reasons for outsourcing (or not) HSPE work.

\begin{tabular}{lrlr}
\hline $\begin{array}{l}\text { Reasons for outsourcing } \\
\text { Code theme }\end{array}$ & $\mathrm{n}$ & $\begin{array}{l}\text { Reasons for not outsourcing } \\
\text { Code theme }\end{array}$ & $\mathrm{n}$ \\
\hline Access expertise & 118 & Sufficient in-house expertise & 26 \\
Provide variety and diversity & 37 & Prohibitive costs & 20 \\
Access physical resources & 27 & Geographical isolation & 5 \\
Accreditation requirement & 10 & No demand & 5 \\
Teacher professional development & 10 & Timetabling difficulties & 4 \\
\hline
\end{tabular}




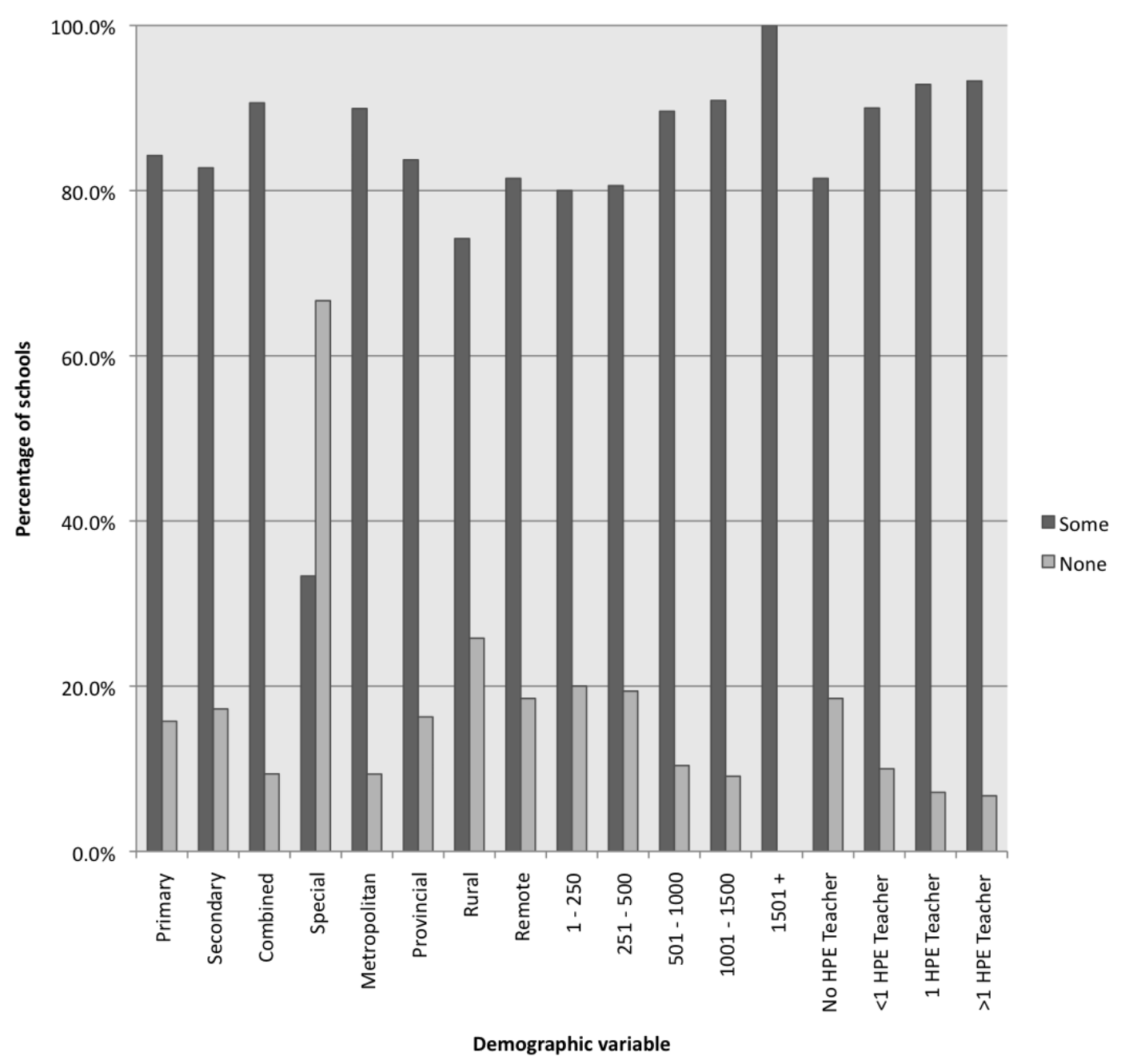

Figure 1. Prevalence of HSPE work outsourcing according demographic variables. 


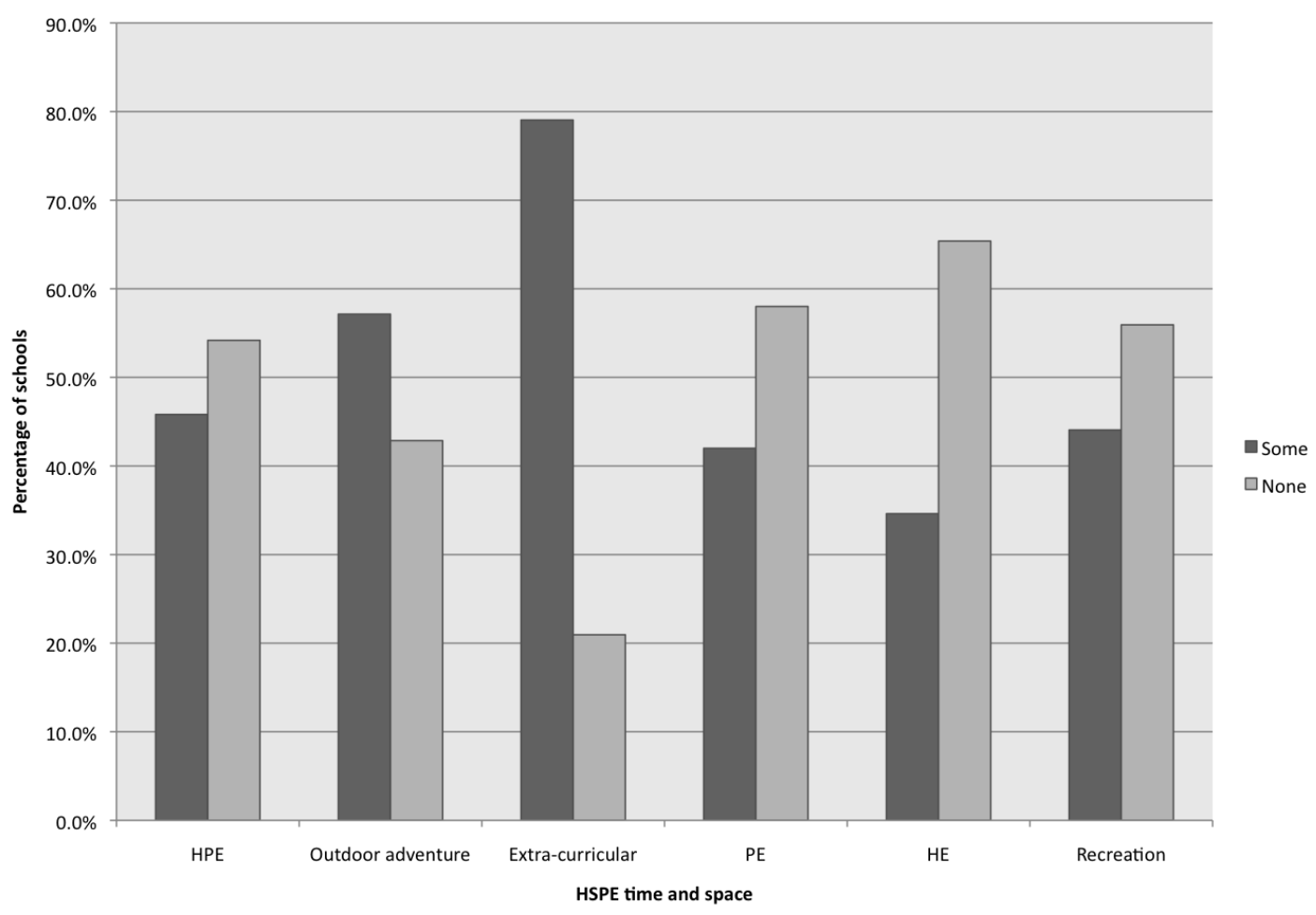

Figure 2. Prevalence of HSPE work outsourcing according to educational time and space. 


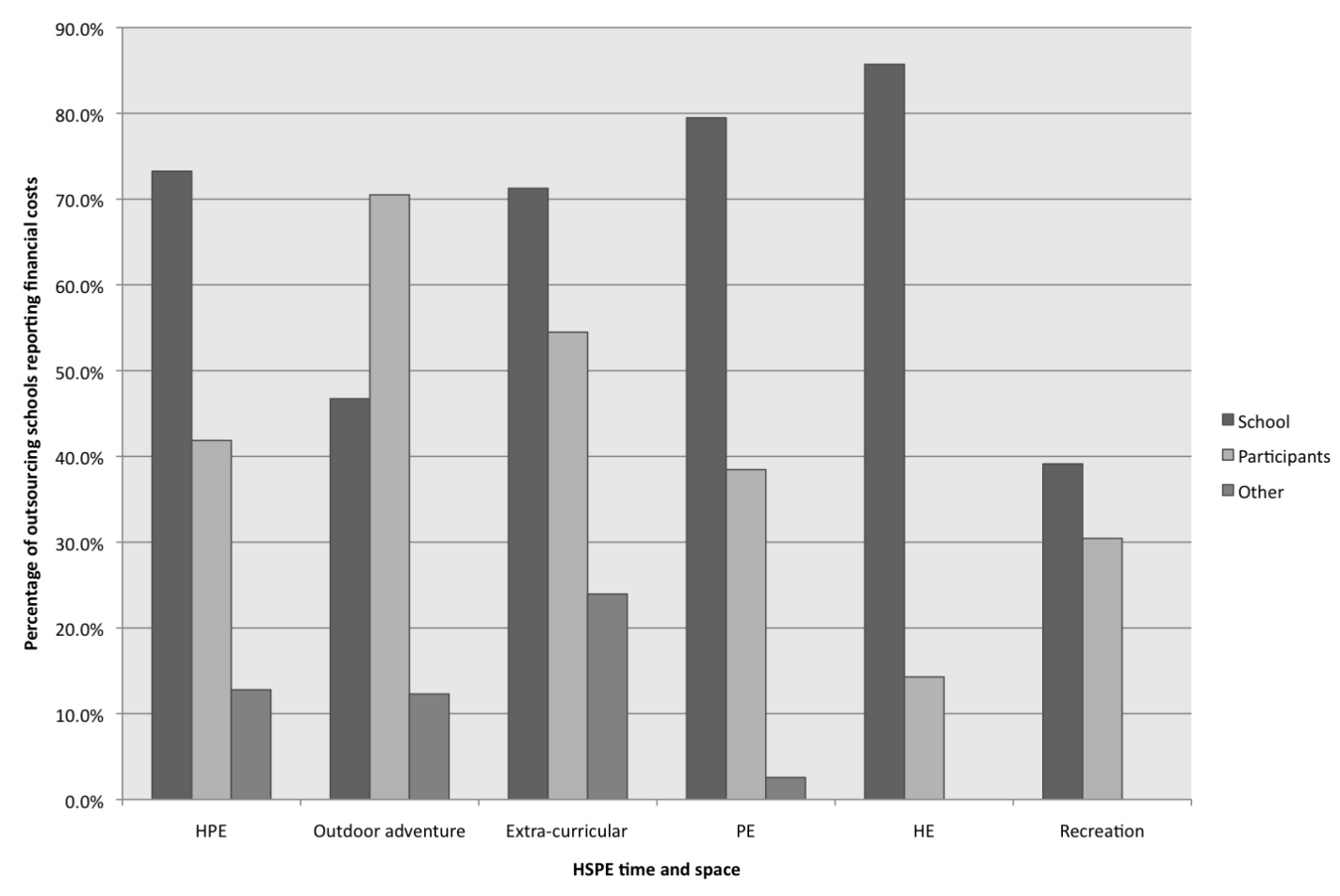

Figure 3. Source of outsourced instruction fees according to educational time and space. 